\title{
Can personality traits explain compliance behaviour? - A study of compliance with water- protection rules in German agriculture
}

\section{Author names and affiliations}

Katja Funke a, *

${ }^{a}$ Martin Luther University Halle-Wittenberg, Institute of Agricultural and Nutritional Sciences, KarlFreiherr-von-Fritsch-Str. 4, D-06120 Halle (Saale), Germany katja.funke@landw.uni-halle.de

Norbert Hirschauer ${ }^{\text {a }}$

${ }^{a}$ Martin Luther University Halle-Wittenberg, Institute of Agricultural and Nutritional Sciences, KarlFreiherr-von-Fritsch-Str. 4, D-06120 Halle (Saale), Germany norbert.hirschauer@landw.uni-halle.de

Denise Peth ${ }^{\mathrm{b}}$

${ }^{\mathrm{b}}$ Georg-August-University Göttingen, Department of Agricultural Economics and Rural Development, Platz der Göttinger Sieben 5, D-37073 Göttingen, Germany

denise.peth@agr.uni-goettingen.de

Oliver Mußhoff ${ }^{b}$

${ }^{\mathrm{b}}$ Georg-August-University Göttingen, Department of Agricultural Economics and Rural Development, Platz der Göttinger Sieben 5, D-37073 Göttingen, Germany

oliver.musshoff@agr.uni-goettingen.de

Oliver Arránz Becker ${ }^{c}$

${ }^{\mathrm{c}}$ Martin-Luther University Halle-Wittenberg, Institute of Sociology, Emil-Abderhalden-Str. 26-27, D06108 Halle (Saale), Germany

oliver.arranz-becker@soziologie.uni-halle.de

* Corresponding author.

Declarations of interest: none

Funding source declaration: The authors gratefully acknowledge financial support from the German Research Foundation (DFG). 


\title{
Can personality traits explain compliance behaviour? - A study of compliance with water- protection rules in German agriculture
}

\begin{abstract}
Going beyond the rational choice approach used in conventional economics of crime, the question arises whether psychological personality traits analysis can contribute to a better understanding of noncompliance and, eventually, to the prevention of illicit behaviours. This study investigated how personality traits are related to compliance with environmental regulation in agriculture. The object of study was a water-protection rule that required farmers using fertilising to keep it a minimum distance away from nearby water bodies. Self-interested infringements can cause serious environmental damage to waters (negative externalities) through nitrogen runoff. In a survey among German farmers, we employed a 10-item version of the Big Five Inventory to measure the traits that are used as predictor variables in a regression analysis. The outcome variable was the farmers' compliance behaviour in a business management game where rule-breaking was more profitable than rule-abidance. Some noteworthy findings were observed in the surveyed sample. (i) Neuroticism was positively related to 'overall compliance', measured as a binary yes/no variable; that is, more anxious farmers were less prone to rule-breaking. Surprisingly, however, a positive relationship between neuroticism and compliance was not found when looking separately at the deviant subgroup; here, greater neuroticism was associated with more severe rule violations, in terms of illicitly fertilised acreage. (ii) In the deviant subgroup, as might have been expected, higher levels of conscientiousness were associated with less severe rule-violations. Contrary to expectations, again, higher levels of agreeableness were linked to more severe non-compliance. A substantial positive relationship was found between extraversion and the severity of non-compliance, in accordance with ex-ante expectation. For openness to experience, no noteworthy results were obtained. The results indicate that agents with heterogeneous personality traits might react differently to identical economic and institutional environments. Moreover, it is suggested that, other than traits, there is another quality in agents (e.g. social control) that may have a decisive influence on their belonging to the compliant or non-compliant subpopulation. Farmers' responses to changes brought forward by regulators who aim to prevent rule-breaking might therefore differ as well.
\end{abstract}

\section{Keywords}

Big Five; personality psychology; environmental protection; behavioural psychology; non-compliance; nitrogen runoff 


\section{Introduction}

\section{Problem background}

Policy interventions aimed at changing agents' behaviours can be divided into regulatory/mandatory, economic and informative measures (Vatn, 2005; Bemelmans-Videc, Rist, \& Vedung, 2007). A particularly important behaviour with regard to the environment is farmers' fertilising behaviour. Nitrogen fertilising is responsible for nearly $80 \%$ of nitrogen emissions in surface waters in Germany (SRU, 2015). An important mandatory measure to mitigate damages to water ecosystems is the minimum-distance rule in the German Fertilizer Ordinance (DüV). Up to 2017, a restriction involving a three-metre minimum distance to the upper edge of the embankment of a water body applied to nitrogen fertilisation. In 2017, it was increased to four metres (DüV, 2017). Whereas compliance with the minimum-distance rule mitigates damages, non-compliance increases the negative externalities, such as eutrophication and a consequent decline in biodiversity.

The traditional economics of compliance based on rational choice assumes that agents rationally and self-interestedly strive only for profit (Becker, 1968; Veetil, 2011); that is, people are assumed to calculate and weigh the material costs and benefits of rule-breaking without taking moral norms into account. Accordingly, policy measures aimed at promoting compliance focus on enforcement measures, such as monitoring and sanctioning, that reduce economic temptations and deter rule-breaking. In primary production, besides fines, the cross-compliance (CC) regulation of the European Common Agricultural Policy provides an important sanctioning mechanism. CC links transfer payments, amongst others, to compliance with environmental standards (Meyer, Matzdorf, Müller, \& Schleyer, 2014).

While it can be safely assumed that the probability of non-compliance varies with its expected economic benefits, the behavioural economics of compliance considers that there may be different individual reactions to identical economic incentives. Depending on the situation, multiple utility gains from complying with rules may or may not outweigh an individual's temptation to break them (PinstrupAndersen, 2005); that is, compliance behaviour is seen as depending not only on material incentives, but also on social control and internalised values because agents pursue multiple goals and strive not only for profits, but also for social recognition and consistency with their identity and internalised social norms (Benz, 2009; Akerlof \& Kranton, 2010; Grüner \& Hirschauer, 2018). The impact of social norms can be reinforced through social control and social comparisons (e.g. Bartke, Friedl, Gelhaar, \& Reh, 2017), including role models (Bandura \& Walters, 1969). Striving for conformity with external social expectations, and consistency with internalised norms, can limit people's self-interest (bounded selfinterest; e.g. Grüner \& Hirschauer, 2018). Besides the impact of multiple goals, behavioural analysts also take bounded rationality into consideration (i.e. the fact that economic agents might make decisions that deviate from rational choice; e.g. Simon, 1957; Gigerenzer \& Selten, 2002). Measures such as nudging or boosting policies (Bond, 2009; Katsikopoulos, 2014), may be promising 'soft' tools for steering the behaviour of multi-goal and bounded-rational decision-makers towards more sustainable 
economic activities (Czap, Czap, Lynne, \& Burbach, 2015; Schubert, 2017). For example, in a study of farmers, Peth, Musshoff, Funke, and Hirschauer (2018) reported that the preventive effects of positive reinforcement (i.e. nudging) depend on the framings that address social norms and comparisons.

Going beyond the behavioural drivers resulting from material incentives, social control and internalised values, psychological personality trait theory assumes that human behaviour is influenced by personality traits that are believed to be more or less stable in situations and over a lifetime (CobbClarc \& Schurer, 2012; Anusic \& Schimmack, 2016). Considering the idiosyncratic traits of economic agents, in addition to behavioural drivers in the form of incentives, social control and internalised values, might therefore contribute to a better understanding of compliance behaviour. The most well-known approach to traits is the 'Big Five' model (Allport \& Odbert, 1936). This describes individuals by using five personality dimensions: neuroticism, extraversion, openness to experience, agreeableness and conscientiousness. (1) Neuroticism captures an individual's emotional stability, and the way in which emotions (especially negative ones) are experienced. (2) Extraversion assesses interpersonal behaviour, and includes aspects such as self-confidence. (3) Openness to experience captures an individual's willingness to engage in novel experiences and ideas. (4) Agreeableness subsumes facets such as altruism and prosocial behaviour. (5) Conscientiousness captures a purposive and systematic way of making plans and organising and conducting tasks (Gerber, Huber, Doherty, \& Dowling, 2011).

A number of previous studies have been concerned with the relationship between idiosyncratic personality traits and attitudes towards environmental issues, as well as compliance behaviour. However, the results of these studies are somewhat contradictory and inconsistent. In a regression analysis, Milfont and Sibley (2012) reported a positive association of agreeableness, conscientiousness and openness to experience with a positive attitude towards protecting the environment. In contrast, greater environmental value, in the form of protecting the environment, measured by a single value item, is linked with lower extraversion. Markowitz, Goldberg, Ashton, and Lee (2012) found moderate positive relations between the trait openness and self-reported pro-environmental behaviour. Other studies have revealed moderate positive correlations between agreeableness and openness to experience with nature relatedness, which describes "individual levels of connectedness with the natural world" (Nisbet, Zelenski, \& Murphy, 2008, p. 718). In a study regarding people's choices among alternative courses of action for power generation in wind farms, the facets altruism and trust of the personality trait agreeableness and the facet feelings of the trait openness were positively related to environmental concerns, in terms of a preference for high-powered turbines that require less surface of a footprint (Farizo, Oglethorpe, \& Soliño, 2016). In a structural regression model, Hirsh (2010) found that higher levels of neuroticism, openness, agreeableness and conscientiousness are related to greater environmental concerns. In contrast, no substantial linkage was observed for extraversion; however, it cannot be ruled out that there is a weak association that may not reach statistical significance in certain studies. Comparable findings were reported by Kvasova (2015) for the traits neuroticism, extraversion, agreeableness and conscientiousness and their positive associations with pro-environmental tourist 
behaviour using structural equation models. Moreover, Hirsh and Dolderman (2007) reported that agreeableness and openness to experience are positively related to environmentalism.

Studies that have analysed the general relationship between personality traits and social behaviour have revealed that neuroticism has a relatively stable positive relation to delinquent behaviour (Amelang, 1986; Eysenck \& Eysenck, 1987). Neuroticism, agreeableness and conscientiousness show a relationship to crime, depending on the kind of violation. For example, the facet scales altruism and compliance of agreeableness are strongly negatively correlated with interpersonal violence. In hierarchical regressions, Fiddick, Brase, Ho, Hiraishi, Honma, and Smith (2016) showed that agreeableness and conscientiousness are associated with tendencies to obey or break social contract rules (rules that regulate social exchanges) or precaution rules (rules for avoiding or mitigating some type of hazard). Low agreeableness is associated with higher willingness to break precaution rules, whereas low conscientiousness is related to increased violations of social contract rules. Moreover, results from meta-analyses have reported strong links between conscientiousness and agreeableness and antisocial and aggressive behaviour (Jones, Miller, \& Lynam, 2011). Antisocial behaviour has been found to be negatively associated with agreeableness and conscientiousness, and only slightly positively associated with neuroticism. With respect to aggressive behaviour, extraversion, openness, agreeableness and conscientiousness exhibit negative relationships with antisocial and aggressive behaviours.

In primary production, as in other fields, the appeal of the law is evidently not always sufficient to prevent profitable illicit behaviours, such as the breaking of environmental protection rules. However, even the costly measures of environmental law enforcement, such as monitoring and sanctioning, do not always suffice in preventing rule-breaking and related negative externalities (e.g. Dowd, Press, \& Huertos, 2008). The prerequisite of better law enforcement and prevention is therefore a better understanding of what makes heterogeneous primary producers break, or not break, rules. Unfortunately, little is known regarding the determinants of individual farmers' (non-)compliance with water protection rules (and in particular the minimum-distance rule) because empirical research in this sensitive field is hampered by high access barriers and the agents' reluctance to provide information. Furthermore, to our knowledge, there are no studies that have used a personality trait perspective to account for the idiosyncrasies of individual farmer's that might influence compliance and, in particular, compliance with water-protection rules. This, however, promises direct insight into why and how agents with heterogeneous personality traits might react differently to identical economic and institutional environments and changes in these environments.

\section{Study objective and research hypotheses}

In the literature, the most meaningful and consistent findings regarding environmental attitudes and behaviours have been reported for the traits of agreeableness and conscientiousness. The traits agreeableness, conscientiousness and openness to experience are generally positively related to pro- 
environmental behaviours and concerns, and negatively related to deviant behaviours, such as rulebreaking and antisocial or aggressive behaviour. This has led us to assume that these three personality traits are also positively associated with farmers' environmentally-relevant choices in production. Moreover, due to the likewise positive relation of neuroticism, and the negative relation of extraversion, with environmental concerns, we would expect comparable relationships in a farmer's environmental choices.

Against the aforementioned background, this study aimed to analyse the effects of farmers' personality traits on their compliance with the minimum-distance rule by using a business management game (BMG) in which rule-breaking is more profitable than rule-abidance. Two different measurements were obtained for the response variable. The 'overall compliance' in the total sample of experimental subjects was measured as a binary yes/no variable, and the 'severity of non-compliance' in the deviant subgroup was measured through the metric variable 'illicitly fertilised acreage'. Table 1 gives an overview of the research hypotheses regarding the influence of the Big Five on compliance behaviour.

\section{Table 1}

Research hypotheses.

\begin{tabular}{llll}
\hline Hypothesis & $\begin{array}{l}\text { Independent (predictor) } \\
\text { variables }\end{array}$ & $\begin{array}{l}\text { Expected effects on the dependent (outcome) } \\
\text { variables }\end{array}$ \\
\cline { 3 - 4 } & $\begin{array}{l}\text { (a) Probability of non- } \\
\text { compliance in the total } \\
\text { sample }\end{array}$ & $\begin{array}{l}\text { (b) Severity of non- } \\
\text { compliance in the } \\
\text { deviant subgroup }\end{array}$ \\
\hline 1 & $\uparrow$ Neuroticism & $\downarrow$ & $\downarrow$ \\
2 & $\uparrow$ Extraversion & $\uparrow$ & $\uparrow$ \\
3 & $\uparrow$ Openness to experience & $\downarrow$ & $\downarrow$ \\
4 & $\uparrow$ Agreeableness & $\downarrow$ & $\downarrow$ \\
5 & $\uparrow$ Conscientiousness & $\downarrow$ & $\downarrow$ \\
\hline Note $: \uparrow=$ increase, & $\downarrow=$ decrease. & &
\end{tabular}

Note: $\uparrow=$ increase, $\downarrow=$ decrease.

A higher tendency of farmers to be neurotic (Hypothesis 1), open to new experiences (Hypothesis 3), agreeable (Hypothesis 4) and conscientious (Hypothesis 5) was presumed to be linked to a lower probability of non-compliance in the total sample $(a)$ and a lower severity of non-compliance in the deviant subgroup (b). In contrast, a higher tendency of farmers to be extraverted (Hypothesis 2) was presumed to be associated with a higher non-compliance, regardless of the type of measurement of the dependent variable $(a$ and $b)$.

\section{Method and data}

The investigation consisted of two parts. Part 1 included a questionnaire, with questions/statements concerning sociodemographic aspects and farm characteristics, followed by a questionnaire consisting of statements relating to the Big Five personality traits and social desirability. Part 2 was composed of a BMG, based on the behavioural decisions of farmers, that assessed compliance behaviour. Following completion of the BMG, a Holt-and-Laury lottery (HLL; Holt \& Laury, 2002) was given to determine 
the participants' risk attitudes. In the following, the participants of the study and the various measurements are described in detail.

\subsection{Data collection and overview}

\section{$2.2 \quad$ Participants}

Table 2 gives an overview of the variables characterising the sample, and the variables of the following regression analyses. 
Table 2

Survey variables of the sample $(\mathrm{N}=163)$.

\begin{tabular}{|c|c|c|c|c|}
\hline & $M$ & $S D$ & $\min$. & $\max$ \\
\hline \multicolumn{5}{|l|}{$\begin{array}{l}\text { Control variables (sociodemographic aspects and farm } \\
\text { characteristics) }\end{array}$} \\
\hline Share of female participants (in \%) & 7.36 & & 0 & 1 \\
\hline Age (in years) & 38.56 & 12.04 & 17 & 70 \\
\hline Number of household members & 3.75 & 1.50 & 1 & 7 \\
\hline Share of participants with agricultural training (in \%) & 61.35 & & 0 & 1 \\
\hline Share of participants with university degree (in \%) & 58.90 & & 0 & 1 \\
\hline Share of participants with farm income as mainstay (in \%) & 77.30 & & 0 & 1 \\
\hline Share of organic farms (in \%) & 13.50 & & 0 & 1 \\
\hline Share of arable farms (in \%) & 34.97 & & 0 & 1 \\
\hline $\begin{array}{l}\text { Share of participants receiving cross-compliance payments } \\
\text { (in \%) }\end{array}$ & 96.93 & & 0 & 1 \\
\hline Share of participants being a member of an association (in \%) & 69.33 & & 0 & 1 \\
\hline Farm size (in ha) & 182.24 & 303.16 & 6 & 2400 \\
\hline $\begin{array}{l}\text { Self-assessed farm operating success compared to others } \\
(0-100)\end{array}$ & 66.53 & 21.48 & 3 & 99 \\
\hline \multicolumn{5}{|l|}{ Other control variables } \\
\hline Social desirability (self-deceptive enhancement) ${ }^{\mathrm{a}}$ & 4.39 & 0.76 & 2 & 6 \\
\hline Social desirability (impression management) ${ }^{\mathrm{a}}$ & 4.68 & 0.89 & 2 & 6 \\
\hline Self-assessed law-abiding behaviour ${ }^{\mathrm{b}}$ & 7.36 & 1.93 & 1 & 10 \\
\hline Risk attitude (HLL value) ${ }^{c}$ & 5.02 & 1.64 & 0 & 10 \\
\hline \multicolumn{5}{|l|}{ Independent variables (focal variables of interest) } \\
\hline Neuroticism $^{\mathrm{a}}$ & 2.80 & 0.92 & 1 & 6 \\
\hline Extraversion $^{\mathrm{a}}$ & 3.75 & 1.18 & 1 & 6 \\
\hline Openness to experience $\mathrm{a}^{\mathrm{a}}$ & 3.57 & 1.14 & 2 & 6 \\
\hline Agreeableness $^{\mathrm{a}}$ & 3.72 & 0.94 & 2 & 6 \\
\hline Conscientiousness $^{\mathrm{a}}$ & 4.57 & 0.95 & 2 & 6 \\
\hline \multicolumn{5}{|l|}{ Dependent variables } \\
\hline Share of non-compliance in the total sample (in $\%)^{\mathrm{d}}$ & 20.25 & & 0 & 1 \\
\hline Severity of non-compliance in the total sample $\left(\text { in }^{2}\right)^{\mathrm{d}}$ & 406.47 & 900.59 & 0 & 3240 \\
\hline
\end{tabular}

The study was carried out online. The significant advantages of internet studies are their time- and costefficiency (Wright, 2005). In addition, internet studies make it easier to recruit potential respondents (Hewson \& Stewart, 2016). Before starting the survey, the software was pretested, with a focus on its suitability, on a small group of employees from the agricultural faculties of the Martin-Luther University, Halle-Wittenberg and the Georg-August University, Göttingen. Based on the feedback, the software was slightly revised. To control for a possible sequential bias, the questionnaire and the BMG, 
with subsequent HLL, were presented in an alternating order (Part 1 first, followed by Part 2, and vice versa). Participation was on a voluntary basis. To circumvent the problem of biased self-reporting on sensible questions, we guaranteed anonymity, privacy and also included the social desirability scale proposed by Winkler, Kroh, and Spiess (2006; see Subsection 2.5.1) to control for socially desirable answers.

The web-based study with farmers was conducted in December 2016. Seven days after the start, an e-mail reminder was sent. Overall, 837 farmers were approached by e-mail via a mailing list from the Farm Management Group of the Faculty of Agricultural Sciences at the Georg-August University, Göttingen. The duration of the investigation amounted to approximately 35 minutes, on average. In total, 163 farmers participated in the survey, yielding a response rate of $19.47 \%$ with complete data. The final sample included more males $(92.64 \%)$ than females $(7.36 \%)$. The mean age of the respondents was 38.56 years. The average household size amounted to 3.75 persons. A total of $61.35 \%$ of the farmers had passed an agricultural training. Moreover, more than half of all the farmers questioned had obtained a university degree. For more than three-quarters of the farmers, farm income represented the main source of income. Of the respondents, $86.50 \%$ cultivated their farms conventionally, and $13.50 \%$ ecologically. With respect to operational form, arable farms dominated, followed by mixed farms. The majority of the farmers received agricultural payments from the EU, and therefore had to comply with environmental protection requirements (CC). Almost $70 \%$ of the farmers belonged to (at least) one association, primarily agricultural and environmental groups. The farm sizes were, on average, 182.24 ha. The self-assessed farm operating success, expressed by a comparison of one's own farm with other farms, on average amounted to 66.53 points on a Likert scale, ranging from 0 (strongly below average success) to 100 (strongly above average success). Furthermore, the respondents' law-abiding behaviour was measured by a single item. Here, the participants had to state to what extent they agreed with the statement, 'I always comply with rules and laws', which was scored on an 11-point Likert scale ( $0=$ I totally disagree, $5=$ neither agree nor disagree, $10=$ I fully agree). The results revealed a rather lawabiding behaviour of the farmers. Regarding participant risk attitudes, measured by the HLL (see Subsection 2.5.2), the farmers tended to be risk averse $(M=5.02, S D=1.64)$. More precisely, $52.1 \%$ of the participants were risk-averse, $36.8 \%$ were risk-neutral and only $11.0 \%$ were risk-seekers. The corresponding questionnaire, containing the sociodemographic and farm characteristics, can be found in Peth et al. (2018).

\subsection{Dependent variable - compliance}

The dependent variable 'compliance' was measured by a BMG, and exists in two ways: (i) share of noncompliance; and (ii) severity of non-compliance. The BMG gathers the decision behaviour of subjects in experimentally-controlled, close-to-real-world, entrepreneurial decision situations, depending on, for example, financial incentives. Using financial incentives may lead to an increase in the internal validity of the BMG (e.g. Levitt \& List, 2009). In setting financial incentives, in the form of prize money, a 
trade-off is created between profit and compliant behaviour, which ensures that the participants reveal their true preferences. A description of the creation of the financial incentives of our BMG is given in Subsection 2.6. In our study, the BMG constituted an extra-laboratory field trial in the form of an internet-based, multi-period, single-player BMG (e.g. Musshoff, Hirschauer, \& Hengel, 2011; Charness, Gneezy, \& Kuhn, 2013; Musshoff \& Hirschauer, 2014). Over four periods, besides the choice of production programme and fertiliser intensity, the participants were asked to make environmental decisions relating to nitrogen fertiliser use in crops on four fields next to surface waters. The application of nitrogen fertiliser was associated with the consideration of the minimum-distance-to-water rule, with the three-metre rule being stated in the instructions. Regarding the distance to water, no constraints were given, and only the participants decided how many metres distance they complied with when applying fertiliser. By using fertiliser, a higher yield and profit was achieved. In this regard, the farmer had to decide between two alternatives: either he chose a low minimum-distance-to-water, which resulted in a higher profit (profit-maximising behaviour) or he complied with the minimum-distance-to-water regulation of three metres (pro-social behaviour). In the BMG, the participants were also confronted with changing external conditions in the form of changing weather conditions (risk of reduced crop yields due to risk of drought stress on several fields) and product prices to make the game even more realistic, and to obfuscate the objective of measuring non-compliant behaviour. Furthermore, we included a variable called the 'price index', which represented the average price of the three possible cultivable crops in a particular period. The design, with individual data on four fields in four periods, led to a panel structure of the data. Appendix A describes the game. A deeper insight into the BMG and its parameters is given in Peth et al. (2018), who analysed the effects of different policy scenarios on farmers' decision behaviours.

\section{$2.4 \quad$ Independent variables - the Big Five}

To measure the Big Five, the participants completed a 10-item version of the Big Five Inventory (BFI; John, Donahue, \& Kentle, 1991). The 10-Item Big Five Inventory (BFI-10; Rammstedt \& John, 2007; Rammstedt, Kemper, Klein, Beierlein, \& Kovaleva, 2013) is an ultra-short, time-efficient and wellestablished version of the BFI that constitutes a reliable and valid instrument for analysing the five personality traits in which individuals differ to a greater or lesser extent. The questionnaire is based on personality theory, and summarises the common core of the different Big Five approaches (for an overview, see Rauthmann, 2017). The BFI-10 consists of two items that measure each of the five personality dimensions of neuroticism, extraversion, openness to experience, agreeableness and conscientiousness. The respondents had to judge the extent to which the statements applied to them. Instead of using a 5-point Likert response scale (cf. Rammstedt et al., 2013), we developed a 6-point Likert scale, ranging from 1 (not correct at all) to 6 (fully correct) to avoid response biases (e.g. error of central tendency; cf. Raithel, 2008). In addition, we only verbalised the end-points of the answer scale so as to obtain interval-scaled data because this has been proven to be successful in practice for many years (Stadtler, 1983; Porst, 2011). To use the Big Five in the later data analyses, we recoded one out of 
two items of the respective five trait dimensions and calculated the mean values for every single dimension, in accordance with the scale manual. The mean values served as scale values in the later data analyses. The items and item recodings of the BFI-10 can be found in Appendix B.

\subsection{Control variables}

\subsubsection{Social desirability}

Due to the lack of consequences for socially undesirable answers resulting from the design of the study, the tendency to give socially desirable answers may have been increased. In this regard, controlling for social desirability is necessary to reduce the problem of the obfuscated true preferences of the farmers (Milfont, 2009; Norwood \& Lusk, 2011). To control for social desirability, we additionally implemented a German short scale (Winkler et al., 2006). The inventory measures two postulated dimensions of social desirability - self-deceptive enhancement (SDE) and impression management (IM) (cf. Paulhus, 1984, 2007) - using three items per dimension. SDE means a tendency to give overly positive self-descriptions towards oneself. In contrast, IM describes the tendency for people to want to impress others. The short social desirability scale demonstrates good reliability, and is both internally and externally valid. Due to its confusing meaning, we slightly altered one item of the IM dimension ('I received too much change from a salesperson without telling him or her' into 'If I received too much change from a salesperson, I wouldn't say anything'). We also changed the original response scale, from a 7-point Likert scale (1 = not correct at all to $7=$ fully correct) to a 6 -point Likert scale, ranging from 1 (not correct at all) to 6 (fully correct), and only verbalised the end-points of the answer scale. Moreover, to conceal the purpose of the social desirability items, we randomly intermixed these items between the items on the questionnaire measuring the Big Five (see Subsection 2.4) by using a random number generator. In the frame of data preparation, we recoded single items of the respective two social desirability dimensions, and calculated the mean values for every single dimension in accordance with the scale manual. The mean values served as scale values in the later data analyses. All items and the item recodings of the social desirability scale are listed in Appendix B.

\subsubsection{Risk attitude}

The participants' risk attitudes were measured using a HLL (Holt and Laury, 2002). This lottery is well established in agricultural economics, and represents one of the most widely used multiple pricelist methods for analysing individual risk preferences (Maart-Noelck \& Musshoff, 2014; Ert \& Haruvy, 2017). The design of the incentivised lottery was based on the original HLL, and allowed differentiation between risk-seeking and risk-averse people. The aim of the HLL was to analyse whether the amount of a possible payment had an effect on the decision behaviour, and thus the risk attitude, of the farmers. Within the HLL, the participants were presented with a sequence of 10 paired consecutive lottery choices. In every choice situation, the participant had to choose between two lotteries (A or B), with varying levels of profit and risk. The probability of winning one of the two available prizes in a particular 
lottery was altered in every decision situation by $10 \%$, starting with a $10 \%$ probability of winning the higher amount and a 90\% probability of receiving the lower amount. Along with these choice sequences, the transition from the less risky (safe) Lottery A to the more risky Lottery B was rewarded with an increasing risk premium. The risk attitudes were measured by an individual's number of safe choices (HLL value), determined by the sum of an individual's overall choices for Lottery A (e.g. Holt \& Laury, 2002; Hirschauer, Musshoff, Maart-Noelck, \& Gruener, 2014; Mußhoff \& Hirschauer, 2016). As a financial incentive, the prize money was placed in the context of a roll of a 10-sided dice. A more detailed description of the HLL and the financial incentives can be found in Peth et al. (2018), Subsection 2.6 and Appendix C.

\subsection{Incentive system}

Besides a global attendance allowance for completing the process, in the form of a voucher for a $€ 30$ Amazon credit, other financial incentives were given to increase participation and ensure that the participants considered their decisions carefully (Guala, 2005). In this regard, measurement of the BMG and the individual risk attitude were governed by an incentive scheme.

In the BMG, prize money was awarded according to the profits earned by the participants. The winners received $€ 100$ for every $€ 100,000$ of total profit generated in the BMG. In the instructions, the participants were informed that $10 \%$ of them would be randomly drawn to win the prize money. The financial incentives were set to create a trade-off between profit-making and compliant behaviour. In doing so, it should have ensured that the participants revealed their true preferences.

According to the HLL, the participants were told that each 15th participant would be randomly chosen. Here, a choice situation was selected by the first roll of the 10 -sided dice for each winner. The second roll of this dice determined the amount paid out, according to the respective lottery the participant decided chose. Altogether, the lottery design offered winnable prize money of between $€ 1$ and $€ 38.50$.

\section{Estimation model}

The dependent (latent) variables of the estimation model reflected the environmental decision behaviour of the farmers in the BMG. Here, the behaviour of the farmers regarding the minimum-distance rule was recorded both categorically (compliance vs. non-compliance) and continuously (illicitly fertilised area in $\mathrm{m}^{2}$ ) for four fields and four game periods, resulting in a panel data design. Non-compliance meant a minimum distance to water of less than three metres; otherwise, the behaviour was assessed as compliance. In the case of non-compliance, the extent of non-compliance (illicitly fertilised area in $\mathrm{m}^{2}$ ) was measured by multiplying the particular field length by the difference between the minimum distance and the self-imposed distance of the farmers. In addition, for every period, we aggregated the amount of illicitly-fertilised area of all fields next to surface waters to provide a total value.

A first look at the distribution of the data in Fig. 1 illustrates that the continuous dependent variable 'severity of non-compliance' shows an excess of zeros. 


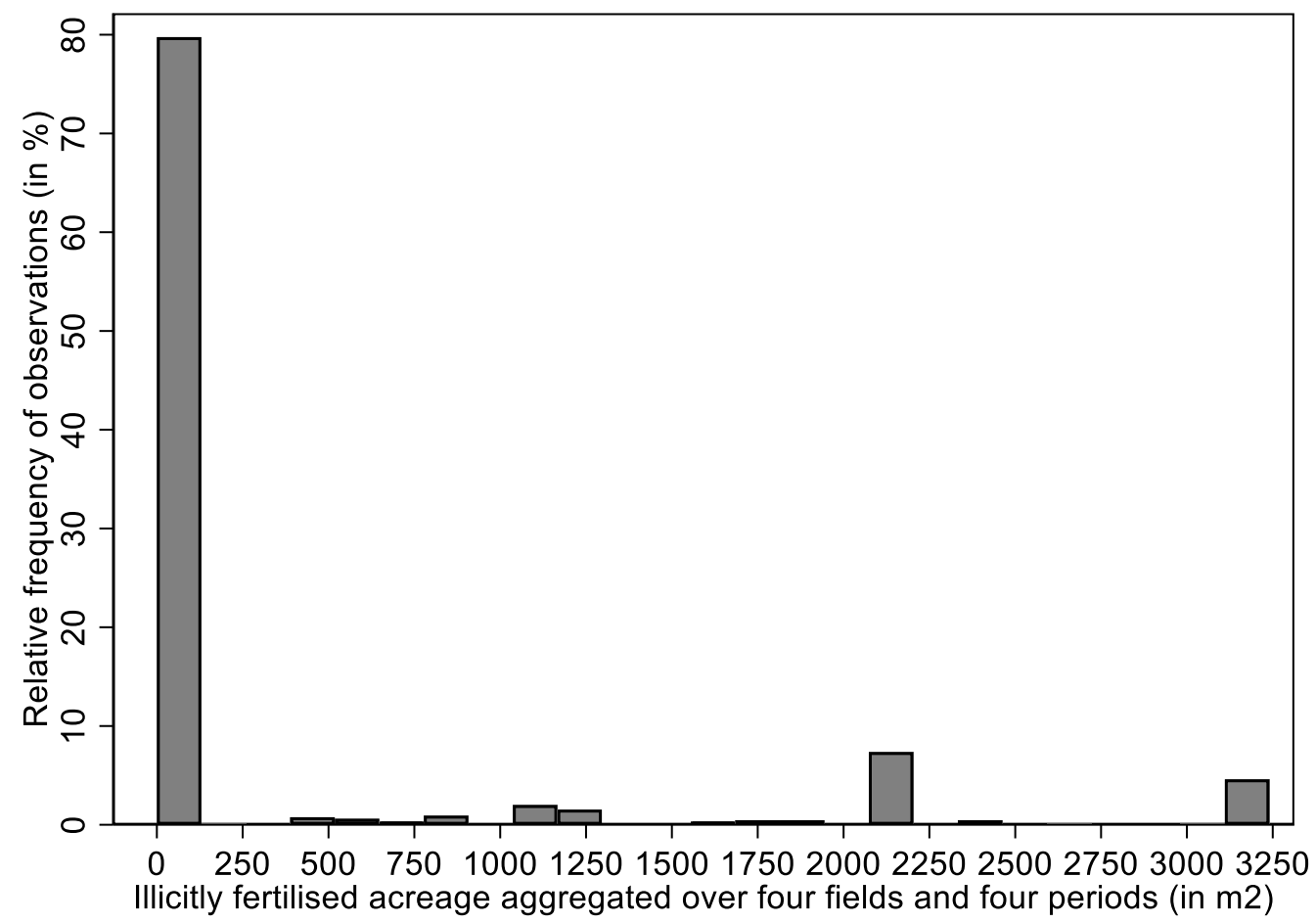

Fig. 1. Distribution of the illicitly fertilised area of four fields and four periods (in $\mathrm{m}^{2} ; \mathrm{N}=652$ ).

A considerable number of zero values indicates more rule-compliant behaviour than rule-breaking behaviour in our sample of farmers. For the non-negative outcome variable, the observations piled up at zero, and therefore this was considered to be left-truncated at zero. Of the farmers, $79.75 \%$ complied with legal regulations. Regarding the severity of non-compliance, deviant behaviour ranged from 150 $\mathrm{m}^{2}$ to $3240 \mathrm{~m}^{2}$. Hence, it appears that two different processes may have been operating here; firstly, the decision whether to comply or not and, secondly, the decision of how far to deviate from the regulation. The complexity of this two-tier process prompted us to refrain from using conventional (e.g. linear) regression models, and instead use an econometric model for limited dependent variables (cf. Frodermann, 2015).

Within the framework of limited variables, so-called 'double-hurdle' models, or two-tier models, consider the differences in the optimal choices of individuals with regard to a dependent variable, $y$. For some people, the optimal choice of $y$ is zero $(y=0)$, whereas for other individuals, the optimal choice of $y$ is $y>0$. Thus, the distribution of $y$ in the population is continuous for $y>0$, but also includes the value zero with positive probability. One of the most commonly used two-tier models - the Tobit model (Tobin, 1958; Wooldridge, 2010) - has the serious limitation that it assumes the choice between $y=0$ and $y>0$, as well as the amount of $y$, given that $y>0$ is to be determined by the same underlying mechanism (i.e. each determinant's effects on both processes are constrained to have equal signs). In our study, we used Cragg's double-hurdle model, proposed by Burke (2009), which represents a generalisation of the Tobit model that is more flexible, and therefore has often been found to be superior (Yen \& Huang, 1996; Keelan, Henchion, \& Newman, 2009). Specifically, the great advantage 
of Cragg's Tobit model over the conventional Tobit model is that it separates the initial decision of $y>$ 0 vs. $y=0$ from the decision of the amount of $y$, given that $y>0$, by assuming two underlying processes. Depending on the research question, within these processes, the determinants may differ from each other.

Regarding the advantages of Cragg's Tobit model, it was deemed a suitable approach for our study because it also considers various properties of the data. First, the model considers the presence of a large number of zero values in the response variables (Cragg, 1971) that lead to strongly skewed distributions of dependent variables. Second, the two processes - probability and severity of noncompliance - can be modelled simultaneously. Third, the model relaxes the constraint of the equal impact of each explanatory factor, including controls, on both processes. In summary, the model was appropriate for answering our research questions by unravelling the potentially two-fold decision process. It also accounted for the panel structure of the data, and fitted well with the theory described in Section 1.

Two-tier models have been prominent in agricultural research. For instance, Katchova and Miranda (2004) investigated the different effects of farm characteristics on marketing contract decisions and decisions regarding quantity, frequency and contract type. Also, Nguyen, Tran, and Mergenthaler (2015) analysed the effect of Vietnamese households' characteristics on expenditure for dairy products. In using double-hurdle models, Ricker-Gilbert, Jayne, and Chirwa (2011) and Martey et al. (2013) reported results for the positive effect of fertiliser subsidies on the demand for commercial fertiliser, as well as the influencing factors on mineral fertiliser adoption (e.g. age, farm size) and use intensity (e.g. membership of farmer association), among farmers in Africa.

Technically, Cragg's double-hurdle model handles two-tier decisions by estimating separate regressions for both processes, represented by two different stochastic variables. According to our hypotheses, in the first tier, a probit model is estimated to analyse a farmer's decision of whether to comply with the minimum-distance requirement $(y=0)$ or not. If the 'hurdle' is crossed (i.e. the farmer decided to deviate from the regulation: $y \neq 0$ ), a truncated regression describes his decision of how far to deviate $(y>0)$.

In light of the aforementioned rationale, Cragg's Tobit model contains both the probit model to determine the probability of the outcome $y>0$, and the truncated normal model for the given positive values of $y$. The corresponding likelihood function (Equation 1) is:

$$
f\left(w, y \mid \boldsymbol{x}_{1}, \boldsymbol{x}_{2}\right)=\left\{1-\Phi\left(\boldsymbol{x}_{1} \boldsymbol{\gamma}\right)\right\}^{1(w=0)}\left[\Phi\left(\boldsymbol{x}_{1} \boldsymbol{\gamma}\right)(2 \pi)^{-\frac{1}{2}} \sigma^{-1} \exp \left\{-\left(y-\boldsymbol{x}_{2} \boldsymbol{\beta}\right)^{2} / 2 \sigma^{2}\right\} / \Phi\left(\boldsymbol{x}_{2} \boldsymbol{\beta} / \sigma\right)\right]^{1(w=1)}
$$

, where $w$ is a binary indicator equal to 1 if $y>0$ and 0 otherwise, $\Phi$ is the standard normal cumulative distribution function, and $1(w=0)$ and $1(w=1)$ are the exponential indicator functions. Compared to the Tobit model, in this model, the probability of $y>0$ and the value of $y$, given that $y>0$, are 
determined by different processes (the vectors $\boldsymbol{\gamma}$ and $\boldsymbol{\beta}$, respectively). In our case, the same set of explanatory variables were used in the first and second tier equations. Thus, the vector $\boldsymbol{x}_{1}$ represents all explanatory variables that were related to the outcome variable, indicating whether non-compliance took place or not $(w)$, while the vector $\boldsymbol{x}_{2}$ includes the same explanatory variables that were related to the outcome variable of the degree of non-compliance, given there was deviation from the regulation $(y)$. With respect to the validity of Cragg's model, the estimated unconditional expected value of $y$ is very close to the result from the general Tobit model.

The probabilities for $y=0$ vs. $y>0$ are the same as in the Tobit model, and are defined as:

$$
\begin{aligned}
& P\left(y_{i}=0 \mid \boldsymbol{x}_{1 i}\right)=1-\Phi\left(\boldsymbol{x}_{1 i} \boldsymbol{\gamma}\right) \\
& P\left(y_{i}>0 \mid \boldsymbol{x}_{1 i}\right)=\Phi\left(\boldsymbol{x}_{1 i} \boldsymbol{\gamma}\right)
\end{aligned}
$$

The expected value of $y$ conditioned on $y>0$ is:

$$
E\left(y_{i} \mid y_{i}>0, \boldsymbol{x}_{2 i}\right)=\boldsymbol{x}_{2 i} \boldsymbol{\beta}+\sigma \lambda\left(\frac{x_{2 i} \boldsymbol{\beta}}{\sigma}\right)
$$

, where $\lambda\left(\frac{x_{2 i} \beta}{\sigma}\right)$ is the inverse Mills ratio and

$$
\lambda\left(\frac{x_{2 i} \boldsymbol{\beta}}{\sigma}\right)=\varphi\left(\frac{\boldsymbol{x}_{2 i} \boldsymbol{\beta}}{\sigma}\right) / \Phi\left(\frac{\boldsymbol{x}_{2 i} \boldsymbol{\beta}}{\sigma}\right)
$$

, where $\varphi$ is the standard normal probability distribution function. A more detailed description of Cragg's Tobit model is given in Burke (2009), in which further specification details are also discussed. In our study, Cragg's double-hurdle was estimated using the Craggit add-on for the statistics software STATA 15 (Burke, 2009).

\section{$4 \quad$ Results and discussion}

\subsection{Inferential interpretation and limitations}

Without questioning whether, in a given research context, there is a chance model upon which to base statistical inference, it seems to be a widespread spontaneous reflex to perform statistical significance testing routines whenever effect sizes are estimated in a regression model. In other words, two essentially different research questions and methods are commonly joined together, but rarely aptly distinguished (Ziliak \& McCloskey, 2008). We should first ask the straightforward question of what is the empirical evidence (finding) in the dataset or study population under investigation. To answer this question, we need to describe the regression model and its findings in terms of estimated coefficients or effect sizes. We should then concern ourselves with inductive inference, and ask what we should reasonably believe after seeing a particular study's findings, and whether and how we can generalise these towards a wider population. Commonly, researchers routinely resort to testing against a null 
hypothesis of no effect (i.e. statistical significance testing based on $p$-values), as an aid to draw statistical inference beyond the single study.

Despite, or rather precisely because of, engrained habits to join together estimating and testing procedures without a second thought (e.g. Gigerenzer, Krauss, \& Vitouch, 2004; Gelman \& Carlin, 2017; Trafimow et al., 2018), it is important to recognise that the latter is based on frequentist statistics. Frequentist statistics is concerned with the signal-to-noise ratio due to randomness, and therefore is inherently based on probability theory and a hypothetical replication of a chance mechanism. Frequentist tools, such as standard errors, $p$-values and confidence intervals, which are but summary statistics of the data at hand, are therefore not applicable if there is no random process of data generation - either randomisation or random sampling (Vogt, Vogt, Gardner, \& Haeffele, 2014, pp. 242, 244).

While the behavioural data in this study were obtained through an experimental BMG, our study was not based on randomisation and an ex ante control over the confounders that would facilitate direct causal inferences. Instead, we resorted to the ex post control of observable confounders through the use of control variables in a statistical model that investigated the relationship between individual traits and the behaviours observed in the BMG. To be viable, the statistical inference would therefore have to be based on random sampling. Unfortunately, our study population was not a random sample drawn from a wider population. Instead, it was a convenience sample, with a strong regional focus and, as in many other studies, a high degree of selection bias. Even a cursory look at certain selected characteristics of our study population, compared to farmers' characteristics in Germany, reveals that we cannot even claim that it is approximately a random sample. For example, only roughly $10 \%$ of the experimental subjects were older than 55 years, while the share is $34 \%$ among German farmers (cf. DBV, 2018). Similarly, $77 \%$ of the experimental subjects indicated that farm income represented their main source of income, whereas this applies to only $48 \%$ of German farmers (DBV, 2018).

Maintaining the $p$-value's probabilistic foundation poses serious conceptual challenges when, as in our study, we do not have a random sample of a defined parent population. In this case, we could not use statistical inference to help generalise towards the intended target population (e.g. comprising all German farmers) to which our hypotheses referred. Because statistical inference can only refer to the undefined study population, and thus may not hold for the target population, we refrained from using conventional significance tests.

There is, however, a rhetorical device called the 'great urn of nature' (cf. Denton, 1988) that is sometimes used to justify using frequentist tools, such as $p$-values, in research contexts where we have non-random samples - or whole populations, for that matter. The great-urn-of-nature argument imagines a 'superpopulation', the parameters of which are assumed to be associated with a stochastic mechanism that generates one observable realisation - the observations in the non-random sample or the population. While the idea of having observed one realisation of a 'true' underlying process may be seen by some as a helpful aid for making meaningful inferences, Denton (1988) noted that this rhetorical device may evoke considerable and understandable reservations among many researchers. Regarding our study, it 
must furthermore be recognised that even the superpopulation argument would fail to facilitate statistical inferences beyond our population of self-selected experimental subjects. Instead, it would imply that there is a specific stochastic process that generated the observations in exactly our convenience sample. Since we did not believe that this idea would be helpful for assessing what kind of inductive generalisations are reasonable, we have displayed and discussed the effect sizes found in the regression, but refrained from carrying out statistical significance testing, and from displaying $p$-values in our results tables. However, accommodating possible expectations emanating from habitual practices, we have displayed the standard errors and $z$-values, which provide the signal-to-noise ratio if 'noise' were to be interpreted as the result of random sampling error.

\subsection{Results of the double-hurdle model}

With respect to the double-hurdle model of Burke (2009), regression analyses were conducted to evaluate the hypotheses from Section 1 . Table 3 summarises the results of both tiers of the model ${ }^{1}$.

\footnotetext{
${ }^{1}$ To check for robustness of the results of the double-hurdle model, we also estimated a baseline model with only the Big Five as independent variables. This analysis led to similar results.
} 
Table 3

Double-hurdle estimates of the effects on the probability of non-compliance (Tier 1) and on the severity of non-compliance (Tier 2).

\begin{tabular}{|c|c|c|c|c|c|c|}
\hline \multirow[t]{2}{*}{ Variable } & \multicolumn{3}{|c|}{$\begin{array}{l}\text { Tier } 1 \text { : Non-compliance } \\
(0=\text { no, } 1=\text { yes }) \\
(\mathrm{N}=652)\end{array}$} & \multicolumn{3}{|c|}{$\begin{array}{l}\text { Tier 2: Severity of non- } \\
\left.\text { compliance (in } \mathrm{m}^{2}\right) \\
(\mathrm{N}=132)\end{array}$} \\
\hline & $A M E$ & $S E$ & $z$-value & $A M E$ & $S E$ & $z$-value \\
\hline Neuroticism ${ }^{a}$ & -0.07 & 0.03 & -2.29 & 212.51 & 190.33 & 1.12 \\
\hline Extraversion $^{a}$ & -0.01 & 0.03 & -0.37 & 271.85 & 123.68 & 2.20 \\
\hline Openness to experience ${ }^{a}$ & -0.00 & 0.02 & -0.02 & -79.19 & 143.72 & -0.55 \\
\hline Agreeableness $^{a}$ & -0.00 & 0.03 & -0.05 & 358.00 & 140.69 & 2.54 \\
\hline Conscientiousness $^{a}$ & -0.01 & 0.03 & -0.31 & -239.17 & 127.61 & -1.87 \\
\hline Self-deceptive enhancement & 0.06 & 0.04 & 1.52 & -340.94 & 190.83 & -1.79 \\
\hline Impression management & -0.07 & 0.03 & -2.35 & 194.97 & 166.32 & 1.17 \\
\hline Female (ref. male) & 0.08 & 0.12 & 0.68 & 104.62 & 673.18 & 0.16 \\
\hline Age (in years) & -0.00 & 0.00 & -1.39 & -8.45 & 23.59 & -0.36 \\
\hline Number of household members & -0.00 & 0.02 & -0.26 & -227.57 & 113.14 & -2.01 \\
\hline $\begin{array}{l}\text { Agricultural training } \\
\text { (ref. no agricultural training) }\end{array}$ & -0.11 & 0.06 & -1.67 & -659.10 & 398.69 & -1.65 \\
\hline Study (ref. no study) & -0.04 & 0.06 & -0.63 & -833.88 & 397.15 & -2.10 \\
\hline $\begin{array}{l}\text { Farm type: full time } \\
\text { (ref. part time) }\end{array}$ & -0.05 & 0.07 & -0.71 & -1416.04 & 405.42 & -3.49 \\
\hline $\begin{array}{l}\text { Cultivation type: organic } \\
\text { (ref. conventional) }\end{array}$ & -0.22 & 0.11 & -2.09 & 408.27 & 589.77 & 0.69 \\
\hline $\begin{array}{l}\text { Operating form: arable farming } \\
\text { (ref. mixed branches) }\end{array}$ & -0.04 & 0.06 & -0.57 & -296.35 & 243.53 & -1.22 \\
\hline $\begin{array}{l}\text { Cross-compliance } \\
\text { (ref. no cross-compliance) }\end{array}$ & -0.22 & 0.18 & -1.18 & -963.63 & 595.38 & -1.62 \\
\hline $\begin{array}{l}\text { Association member } \\
\text { (ref. no association member) }\end{array}$ & 0.07 & 0.07 & 1.02 & 45.43 & 283.33 & 0.16 \\
\hline Farm size & 0.00 & 0.00 & 1.27 & 0.42 & 0.38 & 1.11 \\
\hline $\begin{array}{l}\text { Self-assessed farm operating } \\
\text { success }\end{array}$ & 0.00 & 0.00 & 0.40 & 24.06 & 8.77 & 2.74 \\
\hline $\begin{array}{l}\text { Self-assessed law-abiding } \\
\text { behaviour }\end{array}$ & -0.01 & 0.02 & -0.58 & 100.90 & 71.47 & 1.41 \\
\hline Risk attitude (HLL value) & -0.05 & 0.02 & -2.50 & -230.44 & 62.30 & -3.70 \\
\hline Price index & 0.01 & 0.01 & 1.33 & 12.39 & 33.40 & 0.37 \\
\hline $\begin{array}{l}\text { Questionnaire first } \\
\text { (ref. BMG and HLL first) }\end{array}$ & 0.01 & 0.05 & 0.17 & -442.23 & 212.71 & -2.08 \\
\hline Period 1 & ref. & ref. & ref. & ref. & ref. & ref. \\
\hline Period 2 & -0.00 & 0.01 & -0.13 & 335.30 & 134.53 & 2.49 \\
\hline Period 3 & -0.01 & 0.02 & -0.85 & 412.91 & 131.16 & 3.15 \\
\hline Period 4 & -0.01 & 0.02 & -0.56 & 470.36 & 158.68 & 2.96 \\
\hline
\end{tabular}

Note: $\mathrm{AME}=$ average marginal effect.

$\mathrm{SE}=$ standard error .

a $1=$ not correct at all to $6=$ fully correct. 


\subsubsection{The Big Five and compliance behaviour}

Regarding the use of the Big Five as our variables of interest, in the first tier, neuroticism had a negative relation to the probability to violate the minimum-distance regulation in applying fertiliser. An increase in neuroticism by one unit is linked to a reduction in the probability of an infringement by 7 percentage points. In other words, the more anxious and uncertain the farmers were, the lower the probability that they would show non-compliant behaviour. The result yielded strong evidence in favour of Hypothesis 1(a), but contradicted Hypothesis 1(b), which stated that a decreasing severity in non-compliance in the deviant subgroup is related to an increase in neuroticism. Similar tendencies in neuroticism to inhibit deviant behaviour were also reported by Loeber and Le Blanc (1990). One explanation could be fear of crime, as a trait emotion that is positively correlated with neuroticism (Guedes, Domingos, \& Cardoso, 2018).

The hypothesised associations of openness to experience, agreeableness and conscientiousness with the probability of non-compliance (Tier 1) were quite small. The trivial $z$-values indicated no clear linkage to the probability of non-compliance, and failed to support Hypotheses 3(a), 4(a) and 5(a). The same applied for Hypothesis 3(b), which stated that a lesser severity of non-compliance is associated with increasing openness. Regarding agreeableness and openness, the results did not confirm the findings of other studies, which have reported positive relationships in both personality traits with proenvironmental behaviour (e.g. Pavalache-Ilie \& Cazan, 2018). Rather, they open up the potential for further research.

With respect to the second tier, the severity of non-compliance in the deviant subgroup was positively associated with extraversion $\left(A M E=271.85 \mathrm{~m}^{2}\right)$ and agreeableness $\left(A M E=358.00 \mathrm{~m}^{2}\right)$. For every one-unit increase in extraversion and agreeableness, respectively, the severity of non-compliance increased by $271.85 \mathrm{~m}^{2}$ and $358.00 \mathrm{~m}^{2}$, on average. Thus, for farmers who were sociable and selfconfident, as well as pro-social and trustworthy, the illicitly fertilised area was larger than for famers who scored low in those respective dimensions. It is not clear why this effect was found for agreeableness, as it actually contradicts our initial expectation that increasing agreeableness is associated with decreasing severity of non-compliance in the deviant subgroup (cf. Hypothesis 4(b)). The result could be evidence of the violation-dependence of that trait, according to which agreeableness shows a relationship to crime, depending on the kind of violation (e.g. Amelang, 1986). Nevertheless, the examined association of extraversion was in line with our Hypothesis 2(b). Moreover, for each oneunit increase in conscientiousness, the severity of non-compliance decreased by $239.17 \mathrm{~m}^{2}$. No clear impact on the severity of non-compliance was determined for openness, which is in contrast to our assumptions. Contrary to our expectations, higher neuroticism scores were associated with slightly more deviant behaviour, although this association was small. This finding indicates that anxiety, as a personality disposition, does not always prevent rule-breaking, at least in this group of deviant farmers.

Considering both tiers jointly, diverging effects of extraversion, agreeableness and conscientiousness were visible. All three dimensions exerted a clear association with the severity, but 
not with the probability, of non-compliance. There seemed to be different effects of the personality traits, depending on the group of farmers considered, which can be seen as a justification for our flexible modelling approach using the Craggit model, which treated both tiers as independent.

\subsubsection{Control variables and compliance behaviour}

The analysis of the control variables in the double-hurdle model was of exploratory character, and the results should be regarded as preliminary. However, three results were salient regarding the effects on Tiers 1 and 2, if the effects of each variable are considered jointly for both tiers. The negative relation of agricultural training to both the probability $(A M E=-0.11)$ and severity $(A M E=-659.10)$ of rulebreaking was a remarkable result, which was also found in the study of Peth et al. (2018). Educational effects, in the form of learned knowledge, on environment-related issues and the correction of inefficient skills (e.g. Grüne-Yanoff \& Hertwig, 2016) may have led to the prevention of rule-breaking behaviour. This was in line with the negative linkage between a university degree and the severity of noncompliance in the deviant subgroup $(A M E=-833.88)$. This result is underpinned by Tikka, Kuitunen, and Tynys (2000), who report that students of biology, compared to students in other fields of study (e.g. technology), exhibit the most positive attitudes, and the greatest knowledge, with respect to nature and the environment. With respect to the risk attitudes of farmers, it could be that the more risk-averse farmers are, the lower the probability and severity of non-compliance ( $A M E=-0.05$ vs. $A M E=-230.44)$. This result was comparable to the results from previous studies regarding the association between risk attitudes and (non-)compliance (e.g. Trivedi, Shehata, \& Lynn, 2003; Rezaei, Damalas, \& Abdollahzadeh, 2018). Regarding social desirability, an association of IM (Tier 1) and SDE (Tier 2) with both non-compliance outcomes was found. Thus, possible response bias may be present in the data that warrants a careful interpretation of the results. Specifically, a one-unit increase in the tendency of the farmers to impress others was associated with a decline, by 7 percentage points, in the probability of breaking the minimum-distance rule. With respect to SDE, a one-unit increase in the farmers' tendency to give overly positive self-descriptions tended to decrease the severity of non-compliance by $340.94 \mathrm{~m}^{2}$. One way to reduce possible response biases in questionnaires could be, for instance, the application of the randomised response technique (Warner, 1965), in which sensitive items can be answered, while maintaining confidentiality.

According to Tier 1, the probability of the non-compliant behaviour of organic farmers was 22 percentage points lower than that of conventional farmers. This finding is in line with other findings that have reported that conventional farmers are less environmentally conscious than organic farmers (Läpple, 2013).

According to Tier 2, considering the deviant subgroup, with each person added to a farmer's household, the severity of the illicitly-fertilised area decreased by $227.57 \mathrm{~m}^{2}$, on average. This finding is comparable to the results of Gatersleben, Steg, and Vlek (2002) who reported positive relationships between household size and environmentally-friendly behaviours, such as reduced household energy 
use. Furthermore, deviant full-time farmers in our study broke the rule to a lesser extent than deviant part-time farmers $(A M E=-1416.04)$. For farmers who received direct payments $(\mathrm{CC})$, the illicitly fertilised area decreased by $963.63 \mathrm{~m}^{2}$, compared to farmers with no CC. In this context, a possible effect of $\mathrm{CC}$ as an economic policy measure, using material incentives to steer behaviour in a particular direction, should not be disregarded. A linkage between governance mechanisms, in the form of CC, and the compliance behaviour of farmers has also been reported for other countries (e.g. Herzog, Prasuhn, Spiess, \& Richner, 2008). Moreover, farmers who reported a higher farm operating success showed a greater severity of non-compliance $(A M E=24.06)$. Thus, a high level of self-assessed farm operating success seems to threaten compliance behaviour.

In our study, we also controlled for context effects in presenting Parts 1 and 2 in a different order. Compared to Sequence 2 (BMG and HLL first, followed by the questionnaire), Sequence 1 (questionnaire presented first) was associated with a decrease in the severity of non-compliant behaviour $(A M E=-442.23)$. According to cognitive psychology, this context effect can be traced back to priming effects. Here, the interpretation of information received later may be influenced by information presented earlier, which serves as a cognitive framework or reference point (e.g. Tourangeau, Singer, \& Presser, 2003). With respect to our study, the context of the prior questionnaire items could be related to the decisions in the BMG and the HLL, thus requiring a cautious interpretation of the findings.

A final look at the period of the BMG revealed positive relationships between non-compliant behaviour and Periods 2, 3 and 4, compared to Period 1. Each period increase, compared to the initial Period 1, was related to an increase in the illicitly-fertilised area of $335.30 \mathrm{~m}^{2}, 412.91 \mathrm{~m}^{2}$ and 470.36 $\mathrm{m}^{2}$, respectively. This result may represent evidence for potential learning effects in the subgroup of deviant farmers.

\section{Conclusions}

The non-compliant behaviour of German farmers regarding water-protection rules about nitrogen fertilisation can cause serious environmental damage to surface waters. While the compliance decisions of economic agents are mostly studied from an economics perspective, the question arises whether, and how, psychological trait analysis can contribute to a better understanding of the compliance behaviour of heterogeneous economic agents such as farmers. Our study was based on a non-random convenience sample of German farmers who participated in an incentivised BMG that mirrored the minimum distance-to-water rule of the German Fertiliser Ordinance, and the fact that rule-compliance is costly for farmers. We investigated: (1) how differences in personality traits among the participants were associated with dichotomous compliance behaviour; and (2) how these differences were linked to the severity of non-compliance in the deviant (non-responsive) subgroup.

As ex ante expected, we observed a strong negative association between neuroticism and the probability of non-compliant fertilising behaviour. However, contrary to expectation, a positive relationship linking neuroticism and the severity of non-compliance was found in the non-responsive 
subgroup. That is, while the more anxious farmers seemed to have a lower overall propensity to break the minimum-distance rule, the opposite seemed to hold for the severity of rule-breaking in the deviant subgroup. Interestingly, no substantial associations were found between the four other traits and the participants' general propensity to break the rule. A different picture was observed in the deviant subgroup. Here, we found a substantial positive relationship between extraversion and the severity of non-compliance, in accordance with ex-ante expectation. While being minor, and not really noteworthy, the ex-ante assumption of a negative relationship between openness to experience and the severity of non-compliance was reflected in the behaviour of the deviant subgroup. But contrary to expectation, again, we found a substantial positive association between agreeableness and the severity of the rule violation. Counterintuitively, the deviant participants' pro-social attitudes seemed to be positively related to the severity of the rule-breaking. Finally, as ex ante expected, higher levels of conscientiousness were linked to less severe rule-violations in the deviant subgroup.

While providing interesting indications regarding the relationships that link personality traits with the compliance behaviour of farmers facing costly water-protection rules, our findings, and especially those that are not in line with prior evidence and the corresponding expectations derived from the literature, must be interpreted with caution. First, we must acknowledge that our convenience sample of participating farmers was not a random sample. Due to selection bias, it is difficult to know from which population the sample of participating farmers could be considered as having been drawn. Therefore, inferential conclusions towards a wider population are limited, and cannot be aided by statistical inference. Second, we may not have fully escaped the drawbacks of the stated preference approaches. While having incentivised the BMG to control for the subjects' preferences, we cannot be sure that participants' behaviour in the game was a valid measurement (approximation) of their true, but latent, preferences in the relevant real-life context under consideration. In other words, even the knowledge of a full population would only provide full knowledge of the estimands, that is, the associations linking traits and behaviours in the BMG, but not necessarily of these associations in real life. Therefore, the external validity of our findings is unclear, as the assumption that we have obtained a valid measurement of the subjects' latent preferences must be scrutinised. Moreover, due to the repeated measure of compliance behaviour in the BMG, learning effects may have occurred. To avoid problems of biased decisions in the BMG, for example, the decision situations could be created to be even more realistic, reflecting the closeness to reality of the decision situations, and increasing the game’s complexity (Dieguez-Barreiro, Gonzalez-Benito, Galende, \& Kondo, 2011).

It is nonetheless interesting that the associations between trait and compliance behaviour that we found in our specific study population and context are mostly in line with the qualitative ex-ante assumption, as derived from prior studies that were carried out on a wide variety of different populations and contexts. However, while far from providing substantiated epistemic beliefs contrary to prior propositions, our results differ in some aspects from these propositions. This raises some interesting issues, and indicates promising lines of future research. Finding no substantial associations between 
traits and dichotomous compliance behaviour - except for neuroticism - raises a few questions: Is the insubstantiality of these relationships robust? That is, can they be reproduced in follow-up studies, with new data, and can the existing theory be specified in that these lacking relationships apply to specific subpopulations of economic agents/farmers, but not to others? Similarly, the findings in the deviant subgroup that do not align with ex-ante expectations, such as positive relationships linking both neuroticism and agreeableness to the severity of non-compliance, provoke interesting research questions: Is the apparent division of our study population into responsive (compliant) and nonresponsive (deviant) subgroups, in which personality traits work differently, something that can be reproduced in other and wider populations and compliance contexts? If so, this would provide particularly relevant information for regulators trying to enforce mandatory rules. Besides the suggestion that agents with heterogeneous personality traits react differently to identical decision environments (and changes brought forward by regulators to these environments), it is suggested that, other than traits, there is another quality in the agents that may have a decisive influence on their belonging to the compliant or non-compliant subpopulations. Based on this line of thought, it might be worth studying the influence of social control and bonds to social norms as factors that protect people from giving in to material temptations (Hirschauer \& Scheerer, 2016). In this regard, it would also be interesting to analyse, in different subpopulations, if, or rather how, various policy interventions (e.g. policy nudges) influence agents that differ in traits and protective factors. The detected links between the control variables and behaviours in the BMG provide a basis for the generation of new hypotheses, which could be investigated in follow-up studies. 


\section{References}

Akerlof, G. A., \& Kranton, R. E. (2010). Identity economics: How our identities shape our work, wages, and well-being. Princeton: Princeton University Press.

Allport, G. W., \& Odbert, H. S. (1936). Trait-names: A psycho-lexical study. Psychological Monographs, 47(1), i-171.

Amelang, M. (1986). Sozial abweichendes Verhalten: Entstehung - Verbreitung - Verhinderung. Berlin, Heidelberg: Springer Berlin Heidelberg.

Anusic, I., \& Schimmack, U. (2016). Stability and change of personality traits, self-esteem, and wellbeing: Introducing the meta-analytic stability and change model of retest correlations. Journal of Personality and Social Psychology, 110(5), 766-781.

Bandura, A., \& Walters, R. H. (1969). Social learning and personality development. Psychology. London: Holt Rinehart and Winston.

Bartke, S., Friedl, A., Gelhaar, F., \& Reh, L. (2017). Social comparison nudges-guessing the norm increases charitable giving. Economics Letters, 152, 73-75.

Becker, G. S. (1968). Crime and punishment: an economic approach. Journal of Political Economy, 76(2), 169-217.

Bemelmans-Videc, M. L., Rist, R. C., \& Vedung, E. (Eds.). (2007). Carrots, sticks \& sermons: Policy instruments and their evaluation (4. paperback printing). Comparative policy analysis series. New Brunswick, NJ: Transaction Publ.

Benz, M. (2009). Entrepreneurship as a non-profit-seeking activity. International Entrepreneurship and Management Journal, 5(1), 23-44.

Bond, M. (2009). Decision-making: Risk school. Nature, 461, 1189-1192.

Burke, W. J. (2009). Fitting and interpreting Cragg's tobit alternative using Stata. The Stata Journal, 9(4), 584-592.

Charness, G., Gneezy, U., \& Kuhn, M. A. (2013). Experimental methods: Extra-laboratory experimentsextending the reach of experimental economics. Journal of Economic Behavior \& Organization, 91, 93-100.

Cobb-Clark, D. A., \& Schurer, S. (2012). The stability of big-five personality traits. Economics Letters, $115(1), 11-15$.

Cragg, J. G. (1971). Some Statistical Models for Limited Dependent Variables with Application to the Demand for Durable Goods. Econometrica, 39(5), 829-844.

Czap, N. V., Czap, H. J., Lynne, G. D., \& Burbach, M. E. (2015). Walk in my shoes: Nudging for empathy conservation. Ecological Economics, 118, 147-158. 
DBV (2018). Situationsbericht 2018/19: Trends und Fakten zur Landwirtschaft. Deutscher Bauernverband. Retrieved January 09, 2019, from https://www.bauernverband.de/situationsbericht2018/19.

Denton, F.T. (1988): The significance of significance: Rhetorical aspects of statistical hypothesis testing in economics. In A. Klamer, D.N. McCloskey, \& R.M. Solow (Eds.), The consequences of economic rhetoric (pp. 163-193). Cambridge: Cambridge University Press.

Dieguez-Barreiro, J. H., Gonzalez-Benito, J., Galende, J., \& Kondo, E. K. (2011). The use of management games in the management research agenda. Developments in Business Simulation and Experiential Learning, 38, 83-90.

Dowd, B., Press, D., \& Huertos, M. (2008). Agricultural nonpoint source water pollution policy: The case of California's Central Coast. Agriculture, Ecosystems \& Environment, 128(3), 151-161.

DüV (2017). Verordnung zur Neuordnung der guten fachlichen Praxis beim Düngen Bundesgesetzblatt, Bundesministerium für Ernährung und Landwirtschaft.

Ert, E., \& Haruvy, E. (2017). Revisiting risk aversion: Can risk preferences change with experience? Economics Letters, 151, 91-95.

Eysenck, H. J., \& Eysenck, M. W. (1987). Persönlichkeit und Individualität: Ein naturwissenschaftliches Paradigma. München: Psychologie-Verl.-Union.

Farizo, B. A., Oglethorpe, D., \& Soliño, M. (2016). Personality traits and environmental choices: On the search for understanding. The Science of the Total Environment, 566-567, 157-167.

Fiddick, L., Brase, G. L., Ho, A. T., Hiraishi, K., Honma, A., \& Smith, A. (2016). Major personality traits and regulations of social behavior: Cheaters are not the same as the reckless, and you need to know who you're dealing with. Journal of Research in Personality, 62, 6-18.

Frodermann, C. (2015). Wer arbeitet wie viel? Entscheidungen über den Erwerbsumfang im Partnerschaftskontext. Zeitschrift für Familienforschung, 27(1), 78-104.

Gatersleben, B., Steg, L., \& Vlek, C. (2002). Measurement and Determinants of Environmentally Significant Consumer Behavior. Environment and Behavior, 34(3), 335-362.

Gelman, A., \& Carlin, J. (2017). Some Natural Solutions to the p -Value Communication Problemand Why They Won't Work. Journal of the American Statistical Association, 112(519), 899-901.

Gerber, A. S., Huber, G. A., Doherty, D., \& Dowling, C. M. (2011). The Big Five Personality Traits in the Political Arena. Annual Review of Political Science, 14(1), 265-287.

Gigerenzer, G., Krauss, S., \& Vitouch, O. (2004): The Null Ritual. What You Always Wanted to Know About Significance Testing but Were Afraid to Ask. In D. Kaplan, (Ed.), The Sage handbook of quantitative methodology for the social sciences (pp. 391-408). Thousand Oaks, CA: Sage.

Gigerenzer, G., \& Selten, R. (2002). Bounded rationality: The adaptive toolbox. Cambridge: MIT Press. 
Grüner, S., \& Hirschauer, N. (2018). Crime: Economics of, Different Paradigms. In A. Marciano, \& G. B. Ramello (Eds.), Encyclopedia of Law and Economics (pp. 1-12). New York, NY: Springer.

Grüne-Yanoff, T., \& Hertwig, R. (2016). Nudge Versus Boost: How Coherent are Policy and Theory? Minds and Machines, 26(1), 149-183.

Guala, F. (2005). The methodology of experimental economics. Cambridge: Cambridge University Press.

Guedes, I. M. E. S., Domingos, S. P. A., \& Cardoso, C. S. (2018). Fear of crime, personality and trait emotions: An empirical study. European Journal of Criminology, 40(4).

Herzog, F., Prasuhn, V., Spiess, E., \& Richner, W. (2008). Environmental cross-compliance mitigates nitrogen and phosphorus pollution from Swiss agriculture. Environmental Science \& Policy, 11(7), $655-668$

Hewson, C., \& Stewart, D. W (2016). Internet Research Methods. In N. Balakrishnan, T. Colton, B. Everitt, W. W. Piegorsch, F. Ruggeri, \& J. L. Teugels (Eds.), Wiley StatsRef: Statistics reference online (pp. 1-6). Hoboken, NJ: John Wiley \& Sons, Inc.

Hirschauer, N., Musshoff, O., Maart-Noelck, S. C., \& Gruener, S. (2014). Eliciting risk attitudes - how to avoid mean and variance bias in Holt-and-Laury lotteries. Applied Economics Letters, 21(1), 3538.

Hirschauer, N., \& Scheerer, S. (2016). Protective Factors. In A. Maricano \& G. B. Ramello (Eds.), Encyclopedia of law and economics (pp. 1-11). New York: Springer New York.

Hirsh, J. B. (2010). Personality and environmental concern. Journal of Environmental Psychology, $30(2), 245-248$.

Hirsh, J. B., \& Dolderman, D. (2007). Personality predictors of Consumerism and Environmentalism: A preliminary study. Personality and Individual Differences, 43(6), 1583-1593.

Holt, C. A., \& Laury, S. K. (2002). Risk Aversion and Incentive Effects. American Economic Review, 92(5), 1644-1655.

John, O. P., Donahue, E. M., \& Kentle, R. L. (1991). The Big Five Inventory: Versions $4 a$ and 5. Berkeley, CA.

Jones, S. E., Miller, J. D., \& Lynam, D. R. (2011). Personality, antisocial behavior, and aggression: A meta-analytic review. Journal of Criminal Justice, 39(4), 329-337.

Katchova, A. L., \& Miranda, M. J. (2004). Two-Step Econometric Estimation of Farm Characteristics Affecting Marketing Contract Decisions. American Journal of Agricultural Economics, 86(1), 88102.

Katsikopoulos, K. V. (2014). Bounded rationality: The two cultures. Journal of Economic Methodology, 21(4), 361-374. 
Keelan, C. D., Henchion, M. M., \& Newman, C. F. (2009). A Double-Hurdle Model of Irish Households' Food Service Expenditure Patterns. Journal of International Food \& Agribusiness Marketing, 21(4), 269-285.

Kvasova, O. (2015). The Big Five personality traits as antecedents of eco-friendly tourist behavior. Personality and Individual Differences, 83, 111-116.

Läpple, D. (2013). Comparing attitudes and characteristics of organic, former organic and conventional farmers: Evidence from Ireland. Renewable Agriculture and Food Systems, 28(04), 329-337.

Levitt, S. D., \& List, J. A. (2009). Field experiments in economics: The past, the present, and the future. European Economic Review, 53(1), 1-18.

Loeber, R., \& Le Blanc, M. (1990). Toward a Developmental Criminology. Crime and Justice, 12, 375 473.

Maart-Noelck, S. C., \& Musshoff, O. (2014). Measuring the risk attitude of decision-makers: Are there differences between groups of methods and persons? Australian Journal of Agricultural and Resource Economics, 58(3), 336-352.

Markowitz, E. M., Goldberg, L. R., Ashton, M. C., \& Lee, K. (2012). Profiling the "pro-environmental individual": A personality perspective. Journal of Personality, 80(1), 81-111.

Martey, E., Wiredu, A. N., Etwire, P. M., Fosu, M., Buah, S. S. J., \& Bidzakin, et al. (2013). Fertilizer Adoption and Use Intensity among Smallholder Farmers in Northern Ghana: A Case Study of the AGRA Soil Health Project. Sustainable Agriculture Research, 3(1), 24.

Meyer, C., Matzdorf, B., Müller, K., \& Schleyer, C. (2014). Cross Compliance as payment for public goods? Understanding EU and US agricultural policies. Ecological Economics, 107, 185-194.

Milfont, T. L. (2009). The effects of social desirability on self-reported environmental attitudes and ecological behaviour. The Environmentalist, 29(3), 263-269.

Milfont, T. L., \& Sibley, C. G. (2012). The big five personality traits and environmental engagement: Associations at the individual and societal level. Journal of Environmental Psychology, 32(2), 187195.

Musshoff, O., \& Hirschauer, N. (2014). Using business simulation games in regulatory impact analysis - the case of policies aimed at reducing nitrogen leaching. Applied Economics, 46(25), 3049-3060.

Mußhoff, O., \& Hirschauer, N. (2016). Modernes Agrarmanagement: Betriebswirtschaftliche Analyseund Planungsverfahren (4. überarbeitete und erweiterte Aufl.). München: Vahlen.

Musshoff, O., Hirschauer, N., \& Hengel, P. (2011). Are Business Management Games a Suitable Tool for Analyzing the Boundedly Rational Behavior of Economic Agents? Modern Economy, 2(4), 468478. 
Nguyen, V. P., Tran, H. C., \& Mergenthaler, M. (2015). Effects of Household Characteristics on Expenditure for Dairy Products in Vietnam. International Journal of Research Studies in Agricultural Sciences, 1(5), 1-13.

Nisbet, E. K., Zelenski, J. M., \& Murphy, S. A. (2008). The Nature Relatedness Scale. Environment and Behavior, 41(5), 715-740.

Norwood, F. B., \& Lusk, J. L. (2011). Social Desirability Bias in Real, Hypothetical, and Inferred Valuation Experiments. American Journal of Agricultural Economics, 93(2), 528-534.

Paulhus, D. L. (1984). Two-component models of socially desirable responding. Journal of Personality and Social Psychology, 46(3), 598-609.

Paulhus, D. L. (2007). Measurement and Control of Response Bias. In J. P. Robinson (Ed.), Measures of social psychological attitudes: Vol. 1. Measures of personality and social psychological attitudes (pp. 17-59). San Diego: Academic Pr.

Pavalache-Ilie, M., \& Cazan, A.-M. (2018). Personality correlates of pro-environmental attitudes. International Journal of Environmental Health Research, 28(1), 71-78.

Peth, D., Mußhoff, O., Funke, K., \& Hirschauer, N. (2018). Nudging Farmers to Comply With Water Protection Rules: Experimental Evidence from Germany. Ecological Economics, 152, 310-321.

Pinstrup-Andersen, P. (2005). Ethics and economic policy for the food system. American Journal of Agricultural Economics, 87(5), 1097-1112.

Porst, R. (2011). Fragebogen: Ein Arbeitsbuch (3. Aufl.). Wiesbaden: Springer.

Raithel, J. (2008). Quantitative Forschung. Wiesbaden: VS Verlag für Sozialwissenschaften.

Rammstedt, B., \& John, O. P. (2007). Measuring personality in one minute or less: A 10-item short version of the Big Five Inventory in English and German. Journal of Research in Personality, 41(1), 203-212.

Rammstedt, B., Kemper, C. J., Klein, M. C., Beierlein, C., \& Kovaleva, A. (2013). A Short Scale for Assessing the Big Five Dimensions of Personality: 10 Item Big Five Inventory (BFI-10). Methods, Data, Analyses, 7(2), 233-249.

Rauthmann, J. F. (2017). Persönlichkeitspsychologie: Paradigmen - Strömungen - Theorien. Berlin, Heidelberg: Springer Berlin Heidelberg.

Rezaei, R., Damalas, C. A., \& Abdollahzadeh, G. (2018). Understanding farmers' safety behaviour towards pesticide exposure and other occupational risks: The case of Zanjan, Iran. The Science of the Total Environment, 616-617, 1190-1198.

Ricker-Gilbert, J., Jayne, T. S., \& Chirwa, E. (2011). Subsidies and Crowding Out: A Double-Hurdle Model of Fertilizer Demand in Malawi. American Journal of Agricultural Economics, 93(1), 26-42.

Schubert, C. (2017). Green nudges: Do they work? Are they ethical? Ecological Economics, 132, 329 342. 
Simon, H. A. (1957). Models of man, social and rational: Mathematical essays on rational human behavior in a social setting (4. pr). New York: Wiley.

SRU, S. f. U. (2015). Stickstoff: Lösungsstrategien für ein drängendes Umweltproblem. $\begin{array}{lllll}\text { Sondergutachten. } & \text { Retrieved } & \text { February } & 12, & 2018,\end{array}$ https://www.umweltrat.de/SharedDocs/Downloads/DE/02_Sondergutachten/2012_2016/2015_01_ SG_Stickstoff_HD.html

Stadtler, K. (1983). Die Skalierung in der empirischen Forschung. München: Infratest-Forschung.

Tikka, P. M., Kuitunen, M. T., \& Tynys, S. M. (2000). Effects of Educational Background on Students' Attitudes, Activity Levels, and Knowledge Concerning the Environment. The Journal of Environmental Education, 31(3), 12-19.

Tobin, J. (1958). Estimation of Relationships for Limited Dependent Variables. Econometrica, 26(1), 24.

Tourangeau, R., Singer, E., \& Presser, S. (2003). Context Effects in Attitude Surveys. Sociological Methods \& Research, 31(4), 486-513.

Trafimow, D., Amrhein, V., Areshenkoff , C. N., Barrera-Causil, C. J., Beh, E. J., \& Bilgiç, Y. K. et al. (2018). Manipulating the alpha level cannot cure significance testing. Frontiers in Psychology, 9(699), $1-7$.

Trivedi, V. U., Shehata, M., \& Lynn, B. (2003). Impact of Personal and Situational Factors on Taxpayer Compliance: An Experimental Analysis. Journal of Business Ethics, 47(3), 175-197.

Vatn, A. (2005). Institutions and the environment. Northampton, Mass: Edward Elgar Pub. Retrieved April 25 , 2018 , from http://www.netLibrary.com/urlapi.asp?action=summary \&v=1\&bookid=130523

Veetil, V. P. (2011). Conceptions of rationality in law and economics. European Journal of Law and Economics, 31(2), 199-228.

Vogt, W. P., Vogt, E. R., Gardner, D. C., \& Haeffele, L. M. (2014): Selecting the right analyses for your data: quantitative, qualitative, and mixed methods. New York: The Guilford Publishing.

Warner, S. L. (1965). Randomized Response: A Survey Technique for Eliminating Evasive Answer Bias. Journal of the American Statistical Association, 60(309), 63-69.

Winkler, N., Kroh, M., \& Spiess, M. (2006). Entwicklung einer deutschen Kurzskala zur zweidimensionalen Messung von sozialer Erwünschtheit. DIW Discussion Paper, 579.

Wooldridge, J. M. (2010). Econometric analysis of cross section and panel data (2. ed.). Cambridge Mass. u.a.: MIT Press.

Wright, K. B. (2005). Researching Internet-Based Populations: Advantages and Disadvantages of Online Survey Research, Online Questionnaire Authoring Software Packages, and Web Survey Services. Journal of Computer-Mediated Communication, 10(3). 
Yen, S. T., \& Huang, C. L. (1996). Household Demand for Finfish: A Generalized Double-Hurdle Model. Journal of Agricultural and Resource Economics, 21(2), 220-234.

Ziliak, S. T., \& McCloskey, D. N. (2008). The cult of statistical significance: How the standard error costs us jobs, justice, and lives. Michigan: The University of Michigan Press. 


\section{Appendix A}

\section{Instructions for the Business Management Game (BMG; translated from German into English)}

Over eight periods, you manage an agricultural farm in a region characterised by small-scale agriculture. Your arable land is 15 hectares. The fields you cultivate are mainly located near a river. Some of the fields are threatened by drought.

In the BMG, you have to determine the production programme for your farm eight times. In addition to selecting the crops, you must also consider how much fertiliser you want to use. The yields achieved depend on the amount of the fertiliser used.

At the end of each production period, all products are sold at their current market prices. The profit will be credited to your account. The goal is to achieve the highest possible overall profit by the end of the game.

In the figure to the right, you can see your farmland.

The following crops can be cultivated on the fields:

- Grain maize

- Canola

- Wheat

Please note that each crop must be cultivated on at least one field. For

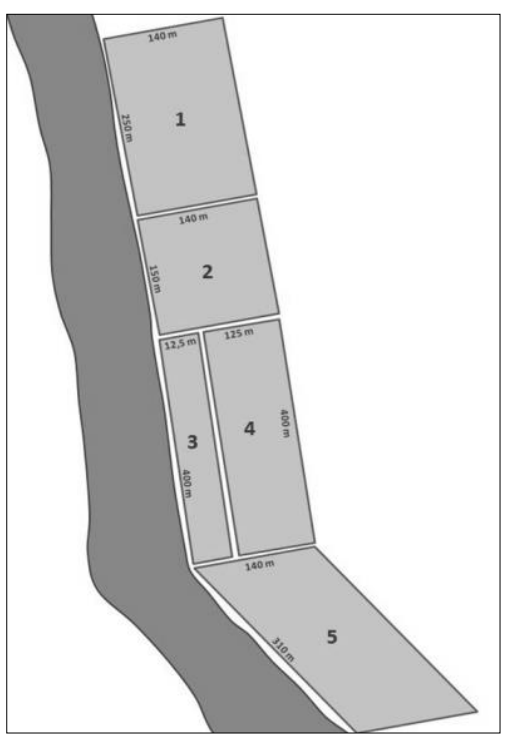
simplification, no specific crop rotations have to be followed.

Some fields have an increased risk of drought stress. This can lead to a yield reduction. A drought stress index of 1 means a 10\% yield reduction for any crop affected. A drought stress index of 2 means a $20 \%$ yield reduction, and a stress index level of 0 means no yield reduction.

\begin{tabular}{|c|c|c|}
\hline Field & Size & Drought stress index \\
\hline 1 & 3.5 ha & 1 \\
\hline 2 & 2.0 ha & 0 \\
\hline 3 & 0.5 ha & 0 \\
\hline 4 & 5.0 ha & 2 \\
\hline 5 & 4.0 ha & 1 \\
\hline
\end{tabular}

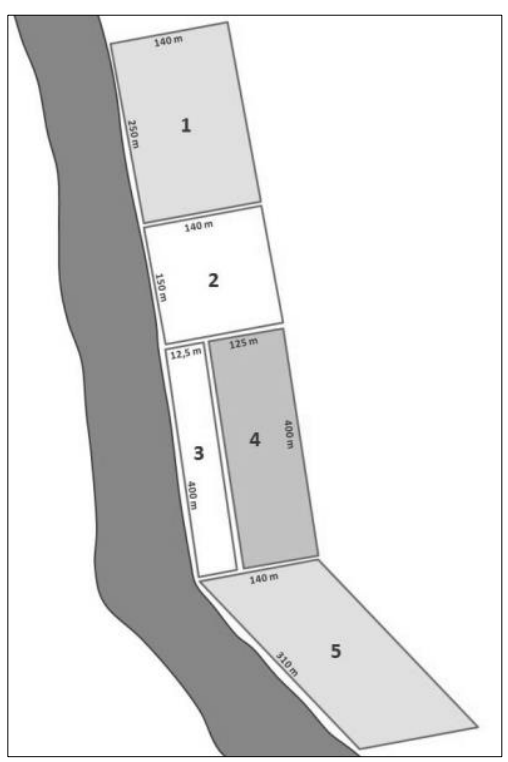


Once you have selected the crops for the individual fields, you have to decide how much fertiliser you would like to use. The following figures show the yield, depending on the amount of fertiliser applied.

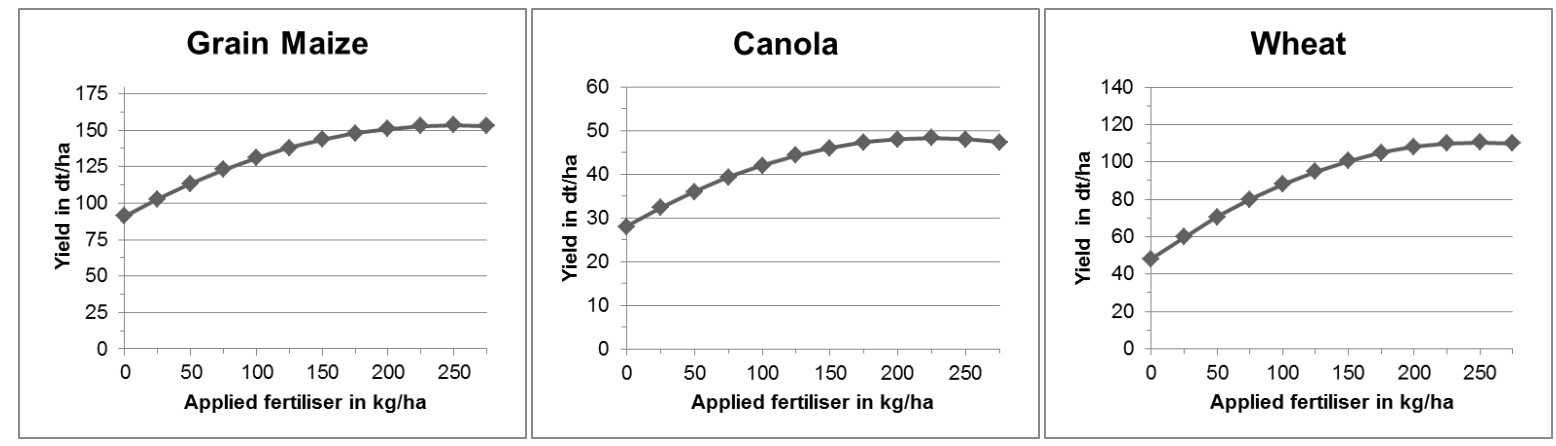

(These figures will also be displayed later, when you are making your decision.)

At the end of the production period, the harvested products are sold at the current market price. These market prices are uncertain and can fluctuate by $10 \%$ from the previous price. This means that, with a probability of $50 \%$ each, the price will increase by $10 \%$ or fall by $10 \%$. The possible price developments over two periods are shown below:

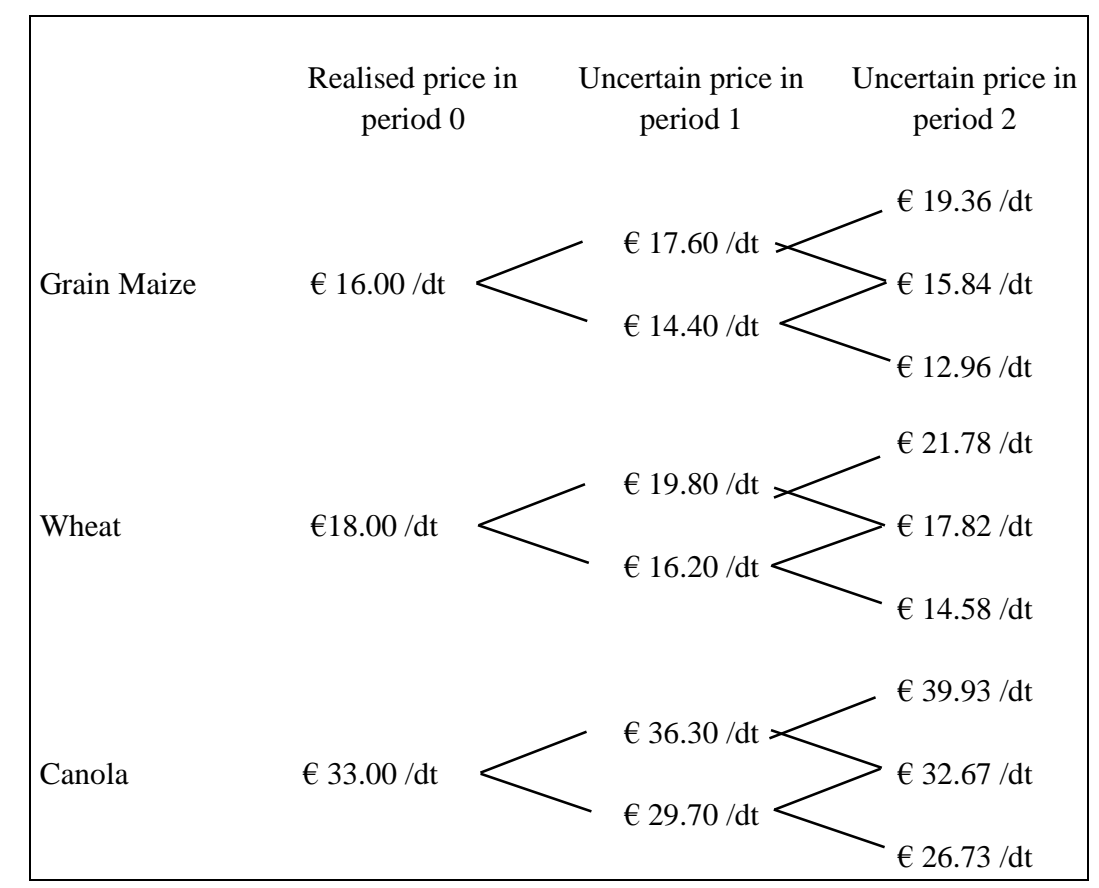

Since the fields are under private ownership, there is no need to pay rent. The following variable costs accrue from cultivation of the individual crops (the fertiliser costs are not included here):

\begin{tabular}{|l|c|}
\hline & Costs per ha \\
\hline Grain maize & $€ 950$ \\
\hline Canola & $€ 820$ \\
\hline Wheat & $€ 800$ \\
\hline
\end{tabular}


The nitrogen fertiliser costs $€ 0.59 / \mathrm{kg}$. For the given fertilisation technology, fertiliser application must legally be carried out at least 3 metres away from any body of water. In each period, you will also receive state transfer payments totalling $€ 300 /$ hectare.

At the beginning of the game, your account balance is $€ 20,000$. If you overdraw your bank account during the game, you can borrow money from your close relatives without interest. As soon as you have the liquidity at the end of a production period, the borrowed capital is automatically repaid.

Before the game begins, you must answer a few questions. This allows you to check that you have understood the basic rules. If you wish to read these instructions again during the game, click on 'Instructions' in the upper right corner of the header.

\section{Control questions}

1. Which crop can be cultivated in the BMG? Please choose one of the following:
$\circ$ Potato
$\circ$ Canola
$\circ$ Rye

2. How much does the use of nitrogen fertiliser cost? Please make your choice from:

$\circ 0.59 € / \mathrm{kg}$

$\circ 0.79 € / \mathrm{kg}$

$\circ 0.99 € / \mathrm{kg}$

3. By what percentage can market prices rise or fall in the following period? Please enter the correct value.

Market prices can rise or fall by $\%$.

(The BMG started after all control questions had been answered correctly.) 


\section{Appendix B}

\section{Items of the BFI-10 and the social desirability scale (translated from German into English)}

\begin{tabular}{|l|l|l|}
\hline $\begin{array}{l}\text { Item } \\
\text { number }\end{array}$ & Item & $\begin{array}{l}\text { Dimension and } \\
\text { polarity of the } \\
\text { item }\end{array}$ \\
\hline & $\begin{array}{l}\text { Introduction given at the start of each item: } \\
\text { How well does the following statement describe you? }\end{array}$ & \\
\hline 1 & I always know why I like things. & SDE+ \\
\hline 2 & I see myself as someone who tends to find fault with others. & A- \\
\hline 3 & I see myself as someone who does a thorough job. & C+ \\
\hline 4 & I am always honest with others. & IM+ \\
\hline 5 & I see myself as someone who is relaxed, handles stress well. & N- \\
\hline 6 & There have been occasions when I have taken advantage of someone. & IM- \\
\hline 7 & If I received too much change from a salesperson, I wouldn't say anything. & IM- \\
\hline 8 & I see myself as someone who is outgoing, sociable. & E+ \\
\hline 9 & I often doubt my own judgement. & SDE- \\
\hline 10 & My first impressions of people usually turn out to be right. & SDE+ \\
\hline 11 & I see myself as someone who is generally trusting. & A+ \\
\hline 12 & I see myself as someone who has few artistic interests. & O- \\
\hline 13 & I see myself as someone who gets nervous easily. & N+ \\
\hline 14 & I see myself as someone who is reserved. & E- \\
\hline 15 & I see myself as someone who has an active imagination. & O+ \\
\hline 16 & I see myself as someone who tends to be lazy. & C- \\
\hline
\end{tabular}

Note: $\mathrm{BFI}-10$ : $\mathrm{N}=$ neuroticism, $\mathrm{E}=$ extraversion, $\mathrm{O}=$ openness to experience, $\mathrm{A}=$ agreeableness, $\mathrm{C}=$ conscientiousness. Social desirability: $\mathrm{SDE}=$ self-deceptive enhancement, $\mathrm{IM}=$ impression management. $+=$ positive polarity, - = negative polarity. 


\section{Appendix C}

\section{Instructions of the Holt-and-Laury lottery (translated from German into English)}

\section{Your decisions in a lottery}

In the following, you have to choose 10 times between two lotteries: Lottery A and Lottery B. The lotteries differ in the amounts you can win.

Example: Let's look at row 4 in the table below. A 10-sided dice is thrown. If you choose Lottery A, you win $€ 20$ if a 1, 2, 3 or 4 is thrown or $€ 16$ if a 5, 6, 7, 8, 9 or 10 is thrown. If you choose Lottery $B$, you win $€ 38.50$ if a $1,2,3$ or 4 is thrown or $€ 1$ if a $5,6,7,8,9$ or 10 is thrown.

Please choose one of the two lotteries in each row.

\begin{tabular}{|c|c|c|c|c|c|}
\hline \multirow[t]{2}{*}{ Decision } & \multicolumn{2}{|r|}{ Lottery A } & \multirow{2}{*}{$\begin{array}{c}\text { Your decision } \\
\mathrm{A} \bigcirc \mathrm{OB}\end{array}$} & \multicolumn{2}{|l|}{ Lottery B } \\
\hline & $\begin{array}{l}\text { Expected } \\
\text { value }(€)\end{array}$ & Prize money - Dice score & & Prize money - Dice score & $\begin{array}{l}\text { Expected } \\
\text { value }(€)\end{array}$ \\
\hline 1 & 16.40 & $\begin{array}{l}€ 20-1 \\
€ 16-2,3,4,5,6,7,8,9,10\end{array}$ & $\mathrm{~A} \bigcirc \bigcirc \mathrm{B}$ & $\begin{array}{cl}\mathbf{\epsilon 3 8 . 5 0} & -1 \\
\mathbf{\epsilon 1} & -2,3,4,5,6,7,8,9,10\end{array}$ & 4.75 \\
\hline 2 & 16.80 & $\begin{array}{l}€ \mathbf{2 0}-1,2 \\
\mathbf{\epsilon 1 6}-3,4,5,6,7,8,9,10\end{array}$ & $\mathrm{~A} \bigcirc \bigcirc \mathrm{B}$ & $\begin{array}{cl}\mathbf{€ 3 8 . 5 0} & -1,2 \\
€ \mathbf{1} & -3,4,5,6,7,8,9,10\end{array}$ & 8.50 \\
\hline 3 & 17.20 & $\begin{array}{l}€ \mathbf{2 0}-1,2,3 \\
\mathbf{\epsilon 1 6}-4,5,6,7,8,9,10\end{array}$ & $\mathrm{~A} \bigcirc \bigcirc \mathrm{B}$ & $\begin{array}{cc}\mathbf{\epsilon 3 8 . 5 0} & -1,2,3 \\
\mathbf{\epsilon 1} & -4,5,6,7,8,9,10\end{array}$ & 12.25 \\
\hline 4 & 17.60 & $\begin{array}{l}€ \mathbf{2 0}-1,2,3,4 \\
€ 16-5,6,7,8,9,10\end{array}$ & $\mathrm{~A} \bigcirc \bigcirc \mathrm{B}$ & $\begin{array}{cl}\mathbf{\epsilon 3 8 . 5 0} & -1,2,3,4 \\
\boldsymbol{\epsilon 1} & -5,6,7,8,9,10\end{array}$ & 16.00 \\
\hline 5 & 18.00 & $\begin{array}{l}\mathbf{\epsilon 2 0}-1,2,3,4,5 \\
\mathbf{\epsilon 1 6}-6,7,8,9,10\end{array}$ & $\mathrm{~A} \bigcirc \bigcirc \mathrm{B}$ & \begin{tabular}{|cl}
$\mathbf{\epsilon 3 8 . 5 0}$ & $-1,2,3,4,5$ \\
$\boldsymbol{\epsilon 1}$ & $-6,7,8,9,10$
\end{tabular} & 19.75 \\
\hline 6 & 18.40 & $\begin{array}{l}€ \mathbf{2 0}-1,2,3,4,5,6 \\
\mathbf{\epsilon 1 6}-7,8,9,10\end{array}$ & $\mathrm{~A} \bigcirc \bigcirc \mathrm{B}$ & $\begin{array}{c}\mathbf{\epsilon 3 8 . 5 0}-1,2,3,4,5,6 \\
\mathbf{\epsilon 1}-7,8,9,10 \\
\end{array}$ & 23.50 \\
\hline 7 & 18.80 & $\begin{array}{l}€ \mathbf{2 0}-1,2,3,4,5,6,7 \\
€ \mathbf{1 6}-8,9,10\end{array}$ & $\mathrm{~A} \bigcirc \bigcirc \mathrm{B}$ & $\begin{array}{cl}\mathbf{\epsilon 3 8 . 5 0} & -1,2,3,4,5,6,7 \\
\mathbf{\epsilon 1} & -8,9,10\end{array}$ & 27.25 \\
\hline 8 & 19.20 & $\begin{array}{l}\boldsymbol{€ 2 0}-1,2,3,4,5,6,7,8 \\
\mathbf{\epsilon 1 6}-9,10\end{array}$ & $\mathrm{~A} \bigcirc \bigcirc \mathrm{B}$ & $\begin{array}{c}\mathbf{\epsilon 3 8 . 5 0}-1,2,3,4,5,6,7,8 \\
\boldsymbol{\epsilon 1}-9,10\end{array}$ & 31.00 \\
\hline 9 & 19.60 & $\begin{array}{l}\mathbf{\epsilon 2 0}-1,2,3,4,5,6,7,8,9 \\
\mathbf{\epsilon 1 6}-10\end{array}$ & $\mathrm{~A} \bigcirc \bigcirc \mathrm{B}$ & $\begin{array}{l}\mathbf{\epsilon 3 8 . 5 0}-1,2,3,4,5,6,7,8,9 \\
\mathbf{\epsilon 1}-10\end{array}$ & 34.75 \\
\hline 10 & 20.00 & $\boldsymbol{\epsilon 2 0}-1,2,3,4,5,6,7,8,9,10$ & $\mathrm{~A} \bigcirc \bigcirc \mathrm{B}$ & $\mathbf{\epsilon 3 8 . 5 0}-1,2,3,4,5,6,7,8,9,10$ & 38.50 \\
\hline
\end{tabular}

